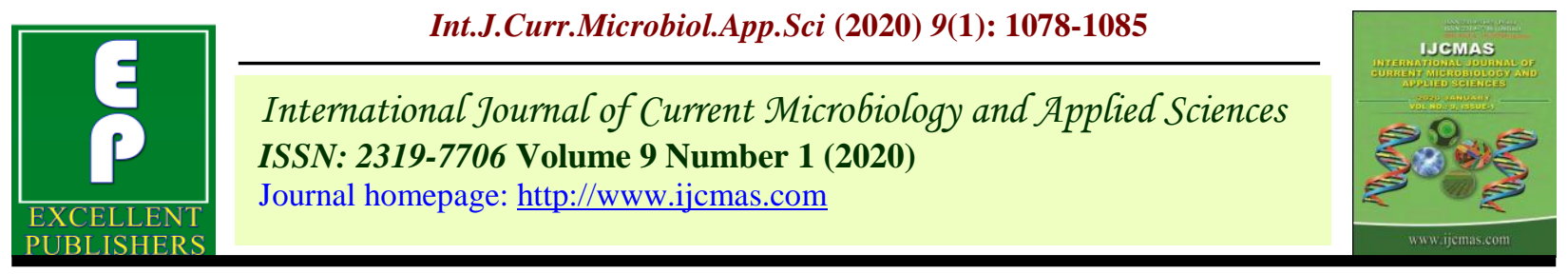

Original Research Article

https://doi.org/10.20546/ijcmas.2020.901.122

\title{
Effect of Age on Semen Characteristics of Hallikar Bulls
}

\author{
R. Prem Kumar ${ }^{1}$, R. Sunitha ${ }^{2 *}$ and T. G. Honnappa ${ }^{3}$ \\ ${ }^{1}$ Veterinary Dispensary, Madanahalli, Kolar, Karnataka, India \\ ${ }^{2}$ Department of Veterinary Public Health and Epidemiology, \\ Veterinary College, Gadag, India \\ ${ }^{3}$ Department of Veterinary Gynecology and Obstetrics, Veterinary College, Banglore, India \\ *Corresponding author
}

A B S T R A C T

Ke ywords

Semen

characteristics, Age,

Spermiogram,

Initial motility,

Hallikar Bulls

Article Info

Accepted:

15December 2019

Available Online:

20 January 2020
The present study was undertaken with the objective to analyze the effect of age on various semen characteristics based on 11,008 ejaculates from 25 Hallikar bulls over a period of 15 years (January 1999 to December 2013). The data on semen collection from individual bulls were sub-clustered under four age groups namely 2-3 years, 3-5 years, 5-7 years and above 7 years. The study concludes that the semen production in Hallikar bulls is influenced by the factor age and has revealed a significant $(\mathrm{P}<0.05)$ effect of age on spermiogram (except initial motility).

\section{Introduction}

Hallikar cattle is considered as one of the premier draught breed of India, popularly known as the champion of draught breeds and it is the pride cattle breed of Karnataka having a history of 600 years (Shekar et al., 2011). They are fast track animals used extensively for dry land agricultural operations and for transportation in rural areas. This breed is considered as the progenitor of the Amrithmahal, Khillar and Kangayam breeds (Kumar et al., 2006). In the recent times, there is deterioration in the form, size, quality, growth, reproduction and production potentialities of Hallikar cattle breed due to changes in the utility and cropping pattern, breeding objectives and agro biodiversity of the breeding tract. The first step for the sustainable use of domestic animal genetic resources is the gathering of information about the genetic variability through characterization of breeds.

A proper exploitation of the genetic potential of the Hallikar bulls and their semen potential needs to be assessed. Such an assessment based on adequate data helps to know the requirement of bulls to cover the breedable cattle in a given area (Karnataka state) and 
also helps the Artificial Insemination programmers to plan a suitable semen production regime to cover the breedable cattle of the area and helps the management to fix the physiological norms of semen production for Hallikar bulls.

Bulls breed round the year, the differences in the ejaculate quality and quantity is influenced by season, age, and year and management practices. These factors by virtue of their effect on quantity and quality of semen ultimately determine the number of straws produced per ejaculate. Similarly, the discard rate of semen during its process for preservation is determined by assessing the influence of these factors on the semen. A clear understanding of the factors which are responsible for the variation should prove valuable in speeding up the economic and more efficient utilization of these bulls at AI centers. Moreover, the semen quality traits of Hallikar bulls still lack a proper scientific documentation. There is no scientific data available on semen quality traits of Hallikar bulls. Hence, in view of these facts the present study was undertaken to assess the effect of age on semen characteristics of Hallikar Bulls.

\section{Materials and Methods}

\section{Study area}

The present study was carried out by utilizing the recorded data, on semen production traits of 25 Hallikar bulls for a period of 15 years (January 1999 to December 2013) at State Semen collection centre, Department of Animal Husbandry and Veterinary Services, Government of Karnataka, Hesseraghatta, Bangalore.

\section{Data collection}

At the farm, all the bulls whose data utilized for the study were maintained under identical housing, feeding, management and health care according to minimum standard protocol (MSP) of Central Monitoring Unit, Government of India. The semen collection was done twice a week from individual bull and 2 ejaculates were obtained with an interval of 15 minutes. A total of 11,008 ejaculates data were collected during the investigation period. Records on semen production were obtained from the collection registers of individual bulls. The data on ejaculate volume, mass activity, sperm concentration, initial motility, post thaw motility. The data accumulated was analyzed to study the effect of age.

\section{Age groups}

The data on semen collection from individual bulls were sub-clustered under four age groups as 2-3 years, 3-5 years, 5-7 years and above 7 years. The number of ejaculates available for 2-3, 3-5, 5-7 and above 7 year age groups were 515, 2226, 2678 and 5589 respectively, as per recorded data. The age of the bulls were determined by the date of birth of individual bull.

\section{Statistical analysis}

The data on 11,008 ejaculate samples from Hallikar bulls, during the period of investigation, were tabulated and analyzed for volume, mass activity, sperm concentration, initial motility, post thaw motility expressed as mean with standard error. The data were analyzed by the method of least square analysis of variance (Harvey, 1979). The sixway classification fixed model was assessed to know the effect of age. Wherever necessary the percentage data were subjected to arc sine transformation before subjecting for the statistical analysis. The least square means pair comparison between groups of means was tested by Duncan's multiple range tests (DMRT). DMRT was done to make specific treatment comparisons for values that were 
found significant by ANOVA according to procedure outlined by Stell and Torrie (1980).

\section{Results and Discussion}

The mean seminal attributes of 25 Hallikar bulls namely the volume, mass activity, sperm concentration, initial motility and post thaw motility are presented in Table- 1 .

\section{Volume}

The mean ejaculate volume of semen based on 11,008 ejaculates of 25 Hallikar bulls was $4.66 \pm 0.01 \mathrm{ml}$ (Table-1) ranged between 0.40 $\mathrm{ml}$ to $13.00 \mathrm{ml}$.

\section{Effect of age on volume of semen}

The mean volume of semen per ejaculate for different age groups in Hallikar bulls are depicted in Table-2. The mean ejaculate volume of $3.74 \pm 0.07,4.34 \pm 0.04,4.53 \pm$ 0.03 and $4.93 \pm 0.02 \mathrm{ml}$ are recorded for bulls aged 2-3, 3-5, 5-7 and above 7 years respectively. The ejaculate volume increased linearly with age. The mean ejaculate volume differed significantly among age groups $(\mathrm{P}<0.05)$. Significantly lower mean ejaculate volume of $3.74 \pm 0.07 \mathrm{ml}$ was recorded in bulls aged 2-3 years as compared to bulls aged 3-5, 5-7 and above 7 years. While the highest ejaculate volume of $4.93 \pm 0.02 \mathrm{ml}$ was registered in bulls above 7 years.

\section{Mass activity (mass motility)}

The mean mass activity of semen (0-5 scale) estimated in the present study was $4.32 \pm$ 0.01 (Table-1) with range of 0.50 to 4.50 .

\section{Effect of age on mass activity}

The mean mass activity of semen ejaculates in different age groups of Hallikar bulls are presented in Table-3. The mean mass activity of $3.90 \pm 0.06,4.33 \pm 0.01,4.38 \pm 0.01$ and $4.30 \pm 0.01$ were noticed in bulls aged 2-3, 3$5,5-7$ and above 7 years, respectively. The highest mass activity of $4.38 \pm 0.01$ recorded in 5-7 years age group and lowest value of $3.90 \pm 0.06$ recorded in 2-3 years age group. The mean mass activity increased linearly with age up to 5-7 years and later showed tendency to decrease however, the variations among age groups were significant $(\mathrm{P}<0.05)$.

\section{Sperm concentration}

The mean sperm concentration for Hallikar bulls in the present study was $1048.55 \pm 3.64$ million per millilitre (Table 1) and it ranged from 500 to 2473 million per milliliter.

\section{Effect of age on sperm concentration}

The mean sperm concentration recorded in different age groups of Hallikar bulls are presented in Table-4. The mean sperm concentration increased significantly up to 5-7 years of age and it decreased significantly in the bulls aged above 7 years.

The highest mean sperm concentration of $1155.73 \pm 7.81 \times 10^{6} \% \mathrm{ml}$ and lowest of 972.65 $\pm 4.65 \times 10^{6} \% \mathrm{ml}$ were observed for bulls of 5-7 years and above 7 years respectively. The mean sperm concentration was significantly lower in above 7 years $(972.65 \pm 4.65 \mathrm{x}$ $10^{6} / \mathrm{ml}$ ) as compared those bulls aged 2-3, 3-5 and 5-7 years. However, no significant differences were observed in sperm concentration of bulls aged 2-3 years and 5-7 years.

\section{Initial motility (Pre-freeze motility)}

The overall mean initial motility recorded for Hallikar bulls in the present study was 80.26 \pm 0.11 per cent (Table-1) and ranged from 70.00 to 90.00 per cent. 


\section{Effect of age on initial motility}

The mean per cent initial motility recorded in different age groups of Hallikar bulls are presented in Table-5. The mean initial motility of $80.58 \pm 0.55,80.28 \pm 0.27,80.44$ \pm 0.25 and $80.19 \pm 0.16$ per cent, respectively were recorded for the bulls aged 2-3, 3-5, 5-7 and more than 7 years and the variations in the mean initial motility between age groups was not significant.

\section{Post thaw motility (Post freeze motility)}

The mean post thaw motility recorded in Hallikar bulls was $49.36 \pm 0.07$ per cent (Table-1) with a range of 30.00 to 60.00 per cent.

\section{Effect of age on post thaw motility:}

The mean post thaw motility recorded in different age groups of Hallikar bulls are presented in Table-6. The mean post thaw motility showed an increase in trend with the advance in age. The highest and lowest mean post thaw motility of $49.50 \pm 0.97$ and 48.42 \pm 0.32 per cent was recorded for bulls aged above 7 years and 2-3 years, respectively. The highest mean per cent post thaw motility observed in bulls of above 7 years age, which differed significantly when compared to bulls aged 2-3 years. However, no significant variation in the post thaw motility was observed among bulls aged 3-5 years 5-7 years and above 7 years.

Table.1 Spermiogram in Hallikar bulls $(\mathrm{N}=11008) .($ Mean \pm SE)

\begin{tabular}{|l|l|l|}
\hline Sl.No & Semen attribute & Mean \pm SE \\
\hline $\mathbf{0 1}$ & Volume $(\mathrm{ml})$ & $4.66 \pm 0.01$ \\
\hline $\mathbf{0 2}$ & Mass activity $(0-5$ Scale $)$ & $4.32 \pm 0.01$ \\
\hline $\mathbf{0 3}$ & Sperm concentration $\left(10^{6} / \mathrm{ml}\right)$ & $1048.55 \pm 3.64$ \\
\hline $\mathbf{0 4}$ & Initial motility $(\%)$ & $80.26 \pm 0.11$ \\
\hline $\mathbf{0 5}$ & Post-thaw motility $(\%)$ & $49.36 \pm 0.07$ \\
\hline
\end{tabular}

Table.2 Semen ejaculate volume (ml) in Hallikar bulls of different age groups. (Mean $\pm \mathrm{SE}$ )

\begin{tabular}{|c|c|c|c|c|}
\hline Age group & $\mathbf{2 - 3}$ years & $\mathbf{3 - 5}$ years & $\mathbf{5 - 7}$ years & >7 years \\
\hline Mean \pm SE & $3.74 \pm 0.07^{\mathrm{a}}$ & $4.34 \pm 0.04^{\mathrm{b}}$ & $4.53 \pm 0.03^{\mathrm{c}}$ & $4.93 \pm 0.02^{\mathrm{d}}$ \\
\hline
\end{tabular}

Note: Means bearing any one common superscript do not differ significantly $(\mathrm{P} \leq 0.05)$

Table.3 Semen mass activity in Hallikar bulls of different age groups (Mean \pm SE)

\begin{tabular}{|c|c|c|c|c|}
\hline Age group & $\mathbf{2 - 3}$ years & $\mathbf{3 - 5}$ years & $\mathbf{5 - 7}$ years & $>\mathbf{7}$ years \\
\hline Mean \pm SE & $3.90 \pm 0.06^{\mathrm{a}}$ & $4.33 \pm 0.01^{\mathrm{bc}}$ & $4.38 \pm 0.01^{\mathrm{b}}$ & $4.30 \pm 0.01^{\mathrm{c}}$ \\
\hline
\end{tabular}

Note: Means bearing any one common superscript do not differ significantly $(\mathrm{P} \leq 0.05)$. 
Table.4 Sperm concentration (millions/ml) in Hallikar bulls of different age groups (Mean $\pm \mathrm{SE}$ )

\begin{tabular}{|c|c|c|c|c|}
\hline Age group & $\mathbf{2 - 3}$ years & $\mathbf{3 - 5}$ years & $\mathbf{5 - 7}$ years & $>\mathbf{7}$ years \\
\hline Mean \pm SE & $1145.16 \pm 19.45^{\mathrm{a}}$ & $1089.20 \pm 8.14^{\mathrm{b}}$ & $1155.73 \pm 7.81^{\mathrm{a}}$ & $972.65 \pm 4.65^{\mathrm{c}}$ \\
\hline
\end{tabular}

Note: Means bearing any one common superscript do not differ significantly $(\mathrm{P} \leq 0.05)$

Table.5 Percent Initial motility (\%) in Hallikar bulls of different age groups (Mean \pm SE)

\begin{tabular}{|c|c|c|c|c|}
\hline Age group & $\mathbf{2 - 3}$ years & $\mathbf{3 - 5}$ years & $\mathbf{5 - 7}$ years & $>$ years \\
\hline Mean \pm SE & $80.58 \pm 0.55^{\mathrm{a}}$ & $80.28 \pm 0.27^{\mathrm{a}}$ & $80.44 \pm 0.25^{\mathrm{a}}$ & $80.19 \pm 0.16^{\mathrm{a}}$ \\
\hline
\end{tabular}

Note: Means bearing any one common superscript do not differ significantly $(\mathrm{P} \leq 0.05)$

Table.6 Post-thaw motility (\%) in Hallikar bulls of different age groups (Mean \pm SE)

\begin{tabular}{|c|c|c|c|c|}
\hline Age group & $\mathbf{2 - 3}$ years & $\mathbf{3 - 5}$ years & $\mathbf{5 - 7}$ years & $>$ 7 years \\
\hline Mean \pm SE & $48.42 \pm 0.32^{\mathrm{a}}$ & $49.46 \pm 0.14^{\mathrm{b}}$ & $49.10 \pm 0.17^{\mathrm{ab}}$ & $49.50 \pm 0.97^{\mathrm{b}}$ \\
\hline
\end{tabular}

Note: Means bearing any one common superscript do not differ significantly $(\mathrm{P} \leq 0.05)$

\section{Effect of age on ejaculate volume:}

The mean ejaculate volume of $3.74 \pm 0.07$, $4.34 \pm 0.04,4.53 \pm 0.03$ and $4.93 \pm 0.02 \mathrm{ml}$ are recorded for bulls aged 2-3, 3-5, 5-7 and above 7 years, respectively. This observation indicates that the ejaculate volume increased linearly with age. Significantly lower mean ejaculate volume of $3.74 \pm 0.07 \mathrm{ml}$ was recorded in bulls aged 2-3 years as compared to bulls aged 3-5, 5-7 and above 7 years. While the highest ejaculate volume of $4.93 \pm$ $0.02 \mathrm{ml}$ was registered in bulls above 7 years and volume of ejaculate showed an increasing trend with advance in age of bull to certain physiological standard. This observation is in conformity with the findings of Tripathi and Prabhu (1966) and Basant et al., (1967) who have also observed an increase in ejaculate volume with advance in age in different zebu bulls. A progressive increase in semen volume with age, which maximized to 4.50 $\mathrm{ml}$ at 10 years of age in Hariana bulls
(Tripathi and Prabhu, 1966). Similarly, significantly higher ejaculatory volume of semen in adult Hariana bulls (3-6 years) when compared to young ( 3 years) bulls (Basanth $e t$ al., 1967 and Rhasin, 1968).

Further, Galmessa and Raina (2002), Ahmad et al., (2003), Mandal et al., (2005), Ahmad et al., (2011) and Bhakat et al., (2011) have also reported significantly higher ejaculatory volume of semen in adult Sahiwal bulls as compared to young bulls.

\section{Effect of age on mass activity}

The mean mass activity recorded in different age groups are shown in Table- 3 . The mean mass activity of $3.90 \pm 0.06,4.33 \pm 0.01,4.38$ \pm 0.01 and $4.30 \pm 0.01$ respectively were noticed in bulls aged 2-3, 3-5, 5-7 and above 7 years. The mean massactivity increased linearly with age up to 5-7 years and later showed tendency to decrease, however, the 
variations among age groups were significant $(\mathrm{P}<0.05)$. The highest and lowes mass activity of $4.38 \pm 0.01$ and $3.90 \pm 0.06$ was recorded in bulls 5-7 years age and 2-3 years age respectively. These observations clearly reflect that the age significantly influence the mass activity in bulls. Similar findings have also been reported previously by Galmessa and Raina (2002) who recorded the mean mass activity of $1.96 \pm 0.10,2.55 \pm 0.10$ in $<50$ months and >50 months old Sahiwal bulls, respectively. Further, Mandal et al., (2005) have reported significantly higher mass activity of $2.81 \pm 0.08$ in adult Sahiwal bulls as compared to young bulls (2.54 \pm 0.10). Similarly, Silva et al., (2009) and Bhakat et al., (2011) have also observed significant influence of age on the mass activity in zebu and Sahiwal bulls.

\section{Effect of age on sperm concentration}

The results of the present study revealed that the mean sperm concentration increased significantly up to 5-7 years of age. The mean sperm concentration was significantly lower in above 7 years $\left(972.65 \pm 4.65 \times 10^{6} / \mathrm{ml}\right)$ as compared those bulls aged 2-3, 3-5 and 5-7 years. However, no significant differences were observed in sperm concentration of bulls aged 2-3 years and 5-7 years (Table-4). Similar to the observations of the present study, several studies have also reported that age significantly influence the sperm concentration. A progressive increase in sperm concentration with age up to 10 years of age was reported in Hariana bulls (Tripathi and Prabhu, 1966). The sperm concentration improved significantly with advance in age of bulls (Mathevon et al., 1998; Sudheer, 2000; Galmessa and Raina, 2002, Ahmad et al., 2011). Similarly, Ahmad et al., (2011) in their study on Sahiwal bulls recorded highest sperm concentration in mature bulls (55-100 months of age; $1,281.60 \pm 17.70 \times 10^{6} / \mathrm{ml}$ ) than the younger bulls (25-54 months of age; $\left.1,115.80 \pm 55.90 \times 10^{6} / \mathrm{ml}\right)$. In yet other study in Sahiwal bulls, Mandal et al., (2005) found higher mean sperm concentration in young bulls $\left(1374.10 \pm 69.53 \times 10^{6} / \mathrm{ml}\right)$ than adult bulls $\left(1275.56 \pm 72.98 \times 10^{6} / \mathrm{ml}\right)$. Silva et al., (2009) reported that the age of the bull significantly influenced the volume in the zebu bulls and older bulls (109 to 142 month old) produced more concentrated semen than young bulls.

\section{Effect of age on initial motility}

The mean initial motility of $80.58 \pm 0.55$, $80.28 \pm 0.27,80.44 \pm 0.25$ and $80.19 \pm 0.16$ per cent respectively were recorded for the bulls aged 2-3, 3-5 , 5-7 and more than 7 years and the effect of age of bulls on the mean initial motility was not significant (Table-5). Similar to the above findings, Veerapandian et al., (1992), Ahmad et al., (2003) and Ahmad et al., (2011) have also reported no significant effect of age on initial motility in Kangayam and Sahiwal bulls respectively.

\section{Effect of age on post thaw motility}

In the present study the mean post thaw motility showed an increase in trend with the advance in age. Significantly highest mean post thaw motility of $49.50 \pm 0.97$ was recorded for bulls aged above 7 years as compared to $48.42 \pm 0.32$ per cent in bulls aged 2-3 years. However, no significant variation in the post thaw motility was observed among bulls aged 3-5 years, 5-7 years and above 7 years (Table-6). The available literature did not reveal any information on the effect of year on post thaw motility in Zebu bulls for comparison. However, the results of the present study are in line with the observations of Ramaiah (2000) who have also reported significant linear increase in post thaw motility with age in Jersey bull. The findings of the present 
study indicate better freezability with increasing age in bulls which are producing normal quality semen.

Summary and Conclusion of the present study revealed significant $(\mathrm{P}<0.05)$ effect of age on spermiogram (except initial motility). It was evident that bulls above 5 years perform better, and in young bulls up to 5 years the performance was below the average. Bulls aged above 7 years ejaculated more volume of semen, had highest mass activity and post thaw motility, whereas sperm concentration drastically reduced. Bulls aged 5-7 years ejaculated more volume of semen, had highest mass activity and sperm concentration. Bulls aged 3-5 years had good post thaw motility percentage. However, the effect of age on initial motility was non- significant. Interestingly the young bulls aged 2-3 and 3-5 years has lowest mean volume of semen and mass activity, whereas sperm concentration was higher in bulls aged 2-3 years. The study has clearly indicated above average performance of adult and older bulls. The superior performance of bulls aged 5-7 and above 7 years than all other age groups indicates that judicial culling coupled with proper housing, management and health care helps the exploitation of genetic potential for a prolonged period. This is certainly of considerable importance for conservation of pure indigenous draft breeds.

\section{References}

Ahmad, E., Ahmad, N., Naseer, Z., Aleem, M., Khan, M.S., Ashiq, M. and Younis, M. 2011. Relationship of age to body weight, scrotal circumference, testicular ultra-sonograms, and semen quality in Sahiwal bulls. Tropical Animal Health and Production. 43: 159- 164.

Ahmad, M., Asmat, M.T., Rehman, N.U. and Khan, M.Z. 2003. Semen characteristics of Sahiwal bulls in relation to age and season. Pakistan Veterinary Journal. 23(4): 202- 206.

Basant, B.P. and Tomar, N.S. 1967. Studies on semen characteristics of Hariana and Murrah bulls. Indian Journal of Dairy Science. 20:81-85.

Bhakat, M., Mohanty, T. K., Raina, V. S., GuptA, A. K., Khan, H. M., Mahapattra, R. K. and Sarkar, M. 2011. Effect of age and season on semen quality parameters in Sahiwal bulls. Tropical Animal Health and Production. 43(6):1161-1168.

Galmessa, U. and Raina, V.S. 2002. Effect of age and scrotal circumference on seminal attributes in dairy bulls. Indian Journal of Animal Science. 72(12):1114-1116.

Harvey, W.R. 1979. Least squares analysis of data with unequal subclass number. Agri. Res. Services. USDA. Maryland.

Kumar, S.N., Jayashankar, M.R., Nagaraja, C.S., Govindhaiah, M.G., Saravanan, R and Karthickeyan, S.M.K. 2006. Molecular characterization of Hallikar breed using microsatellite markers. Asian-Aust. Journal of Animal Science. 19(5): 622-626.

Mandal, D.K., Tyagi, S. and Mathur, A,K., 2005. Semen production performance of Sahiwal bulls. Indian Journal of Animal Science. 75(1): 17-19.

Mathevon, M., Buhr, M.M. and Dekkers, J.C.M., 1998 Environmental, management and genetic factors affecting semen production in Holstein bulls. Jornal of Dairy Science. 81: 3321-3330.

Ramaiah, G.T., 2000. Semen production potential of Jersey bulls, M.V.Sc Thesis Submitted to UAS Bangalore.

Rhasin, N.R., 1968. An analysis of the components of variance of quantity of semen ejaculated in Hariana, Nagauri and Gir Bulls. Indian Journal of Dairy Science. 22: 137-142. 
Shekar, M.C., Kumari, J.U., Karthickeyan, S.M.K. and Muthezhilan, R. 2011. Assessment of with-in breed diversity in Hallikar cattle (Bos indicus) through microsatellite markers. Indian Journal of Science and Technology. 4(8): 895898.

Silva, A.R D.A, Ferraudo, A.S., Perecin, D.., Lima, V.F.M.H. 2009. Effect of the age of the bull and the semen collection periods on physical and morphological semen characteristics of European and zebu breeds.de; Sociedade Brasileira de Zootecnia, Viçosa, Brazil, Revista Brasileirade Zootecnia, 38(7): 12181222.

Stell, G.O. and Torrie. 1980. Principles and procedures of statistics. McGraw-Hill Book Co. Ltd. London. pp: 590-593.

Sudheer, S. 2000. Relationship of age and scrotal circumference with the seminal characteristics of crossbred bulls. Indian Journal of Animal Science. 70: 804806.

Tripathi, V. N. and Prabhu, S. S. 1966. Variation in semen quality, reaction time and conception rate due to age of the bull in Haryana cattle. Indian Journal of Dairy Science. 19: 207-210.

Veerapandian, C., Cecilia, C., Rajasekaran, J. and Quayam, S.A. 1992. Testicular biometry and seminal characteristics of Kangayam bulls. Indian Journal of Animal Research. 13(2): 138-140.

\section{How to cite this article:}

Prem Kumar, R., R. Sunitha and Honnappa, T. G. 2020. Effect of Age on Semen Characteristics of Hallikar Bulls. Int.J.Curr.Microbiol.App.Sci. 9(01): 1078-1085. doi: https://doi.org/10.20546/ijcmas.2020.901.122 